Article

\title{
Preparation and Evaluation of Topically Applied Azithromycin Based on Sodium Hyaluronate in Treatment of Conjunctivitis
}

\author{
Qian Chen ${ }^{1,2}$, Chun Yin ${ }^{1,2}$, Jiang $\mathrm{Ma}^{3}$, Jiasheng Tu ${ }^{1,2, *}$ and Yan Shen ${ }^{1,2, *}$ \\ 1 Department of Pharmaceutics, China Pharmaceutical University, 24 Tong Jia Xiang, Nanjing 210009, China; \\ 1621010133@stu.cpu.edu.cn (Q.C.); yinchun8124@gmail.com (C.Y.) \\ 2 Center for Research Development and Evaluation of Pharmaceutical Excipients and Generic Drugs, China \\ Pharmaceutical University, 24 Tong Jia Xiang, Nanjing 210009, China \\ 3 School of Biomedical Sciences, Faculty of Medicine, the Chinese University of Hong Kong, \\ Hong Kong 999077, China; majoriea@163.com \\ * Correspondence: jiashengtu@cpu.edu.cn (J.T.); shenyan19820801@126.com (Y.S.); \\ Tel.: +86-258-327-1305 (J.T.); +86-258-327-1305 (Y.S.)
}

Received: 16 February 2019; Accepted: 11 April 2019; Published: 15 April 2019

\begin{abstract}
Azithromycin (AZI) eye drops containing sodium hyaluronate (SH) were developed to improve the bioavailability of AZI. Interaction between AZI and SH in the AZI-SH formulation was investigated by differential scanning calorimetry, $\mathrm{X}$-ray diffraction, and ${ }^{1} \mathrm{H}$-nuclear magnetic resonance spectroscopy analyses. Moreover, advantages of using $\mathrm{SH}$ as an excipient were investigated by comparing physiological properties and pharmacokinetic behaviors of SH-containing AZI eye drops with that of hydroxypropyl methylcellulose (HPMC)-containing formulation. In addition, safety of the developed AZI-SH eye drops was evaluated by in vitro 3-(4,5-dimethyl-2-Thiazyl)-2, 5-diphenyl-2H-tetrazolium bromide assay (MTT assay) and neutral red uptake assay as well as in vivo eye irritation test and acute toxicity test. The results indicated that AZI formed a complex with $\mathrm{SH}$ under a slightly acidic condition. The area under the curve (AUC) of AZI in SH-containing formulation was 1.58 -fold higher $(P<0.01)$ than that in HPMC-containing formulation due to the interaction between the amine group of AZI and the carboxyl group of $\mathrm{SH}$, despite of the higher viscosity of HPMC-containing formulation. Safety evaluation showed that AZI-SH eye drops caused no obvious eye irritation and acute toxicity. In conclusion, the developed SH-containing AZI formulation possessing advantages of longer retention time and higher drug availability was a promising drug formulation for topical ocular therapy.
\end{abstract}

Keywords: azithromycin; sodium hyaluronate; bioadhesion; eye drops; ocular bioavailability; safety evaluation

\section{Introduction}

The prevalence of conjunctivitis, especially those caused by Chlamydia trachomatis remains very high. It has been reported by World Health Organization (WHO) that there are approximately 300-500 million people who had suffered from trachoma [1]. Azithromycin (AZI) is a new type of semi-synthetic macrolide antibiotic, which shows antibacterial effects to a variety of common pathogenic bacteria and has been used to treat respiratory infections, skin and soft-tissue infections and genital infections [2]. Previous reports have demonstrated that the oral dosage forms of azithromycin were effective for the treatment of eye infections, such as conjunctivitis and other sensitive pathogens [3-5]. However, at least $1.0 \mathrm{~g}$ of AZI was required for each oral dose to ensure the sufficient concentration of AZI in aqueous humor, tears and conjunctiva coat to exert its inhibitory effects. As a consequence, the high 
oral dose of AZI might enhance the risk of side effects due to the high concentration of AZI in other normal tissues [6,7]. Therefore, a topical ophthalmic formulation of AZI with advantages of lower dose frequency, more convenience and better compliance is required, which may also facilitate the reduction of the risk of selecting resistant bacteria [8]. AZI salt form was commonly applied to prepare its aqueous ocular formulation owing to the deficient water solubility $[9,10]$. Nevertheless, the short retention time of effective drugs on the ocular surface has hampered the use of traditional topical ophthalmic formulations. After instillation, the eye's drainage system was activated by exogenous drugs, and blinking and lachrymation significantly accelerated the excretion thus lowering the efficacy of the drugs. On the other hand, to maintain the effective drug concentration in the tear film, more frequent instillations were required, which might cause side effects and result in poor patient compliance [11].

In order to enhance the persistence of AZI in eyes, various mucoadhesive materials possessing precorneal retention properties have been used to improve ocular drug bioavailability, such as sodium hyaluronate (SH), hydroxyl methylcellulose, polyvinyl alcohol, hydroxypropyl methylcellulose (HPMC), carboxyl methylcellulose and polycarbophil [12-16]. AzaSite ${ }^{\circledR}$, by taking DuraSite as drug delivery system, was an ophthalmic AZI formulation on the market to treat bacterial conjunctivitis. Crosslinking acrylic acid resin was used in this system to stay in contact with conjunctiva to prolong the retention of AZI [17,18]. However, eye irritation has been frequently reported in about $1-2 \%$ of patients who received AzaSite ${ }^{\circledR}$ [18]. In the present study, SH with bioadhesive feature and mutual effect was employed in the ophthalmic AZI formulation for the treatment of bacterial infections.

Hyaluronic acid, a kind of natural linear mucopolysaccharide, consists of $\beta-1,4$ glucuronic acid and $\beta-1,3$ acetylglucosamine disaccharides repeat units. Hyaluronic acid has been widely used as an excipient in various drug delivery systems due to its biocompatibility, safety and biodegradability $[19,20]$. It is normally existed in the form of sodium salt, $\mathrm{SH}$, which is a highly hydrophilic and negatively charged polymer with biological adhesion effect [21]. The binding sites of hyaluronate have been identified on the corneal endothelium [22], which contributes to the improved bioavailability of hyaluronate-containing ophthalmic formulation. In addition, $\mathrm{SH}$ has also been proposed capable of reducing ocular surface toxicity and alleviating symptoms of ocular surface damage [23,24].

In this paper, biological adhesion effect of $\mathrm{SH}$ has been demonstrated by investigating the interaction between AZI and SH. The drug retention effect of SH and HPMC was also compared in terms of viscosity and pharmacokinetic properties of AZI eye drops containing HPMC or SH. In addition, the toxicity of AZI eye drops was evaluated by both in vitro and in vivo approaches.

\section{Materials and Methods}

\subsection{Materials}

AZI was bought from Guoguang Pharmaceutical Co., Ltd. (Hangzhou, China). SH (1500kD, Eye-drop Grade) was bought from Freda Biochem Co., Ltd. (Shandong, China). Acetonitrile (HPLC/SPECTRO) was purchased from Tedia Company Inc. (Fairfield, OH, USA). HPMC K100M was obtained from Colorcon (Shanghai, China) and sodium chloride injection was bought from Shandong Huaru Pharmaceutical Co., Ltd. (Shandong, China). All other reagents used in the present study were of analytical grade.

New Zealand albino rabbits (male and female) weighing 2.0-2.5 kg, free of any signs of ocular disease, were purchased from Nanjing Qinglong Mountain Farm (Nanjing, China). All animal experiments were carried out according to the National Institute of Health Guide for the Care and Use of Laboratory Animals and approved by the Animal Ethics Committee of China Pharmaceutical University (SYXK2017-0019, 20 December 2016 to 19 December 2021). 


\subsection{Methods}

\subsubsection{Degradation Kinetics of AZI}

Detailed experimental procedures of degradation kinetics of AZI are included in the Supplementary information.

\subsubsection{Preparation of AZI-SH and AZI-HPMC Complex Powders}

The optimal formulation contained AZI $10 \mathrm{mg}$, SH (1500 kD) $6 \mathrm{mg}$, benzalkonium chloride (BZK) $0.01 \mathrm{mg}$ and ultra-pure water $1 \mathrm{~mL}$. The preparation process was divided into two parts $(100 \mathrm{~mL}$ eye drops as the sample). For the first part, AZI $(1 \mathrm{~g})$ was precisely weighed and dispersed in $40 \mathrm{~mL}$ ultra-pure water and phosphoric acid $(1 \mathrm{~mol} / \mathrm{L})$ was slowly added to adjust $\mathrm{pH}$ to 5.5 with continuous stirring until the AZI dissolved thoroughly. Then, BZK $(1 \mathrm{mg})$ was added and sodium chloride $(2 \mathrm{~mol} / \mathrm{L})$ was used to adjust the osmotic pressure to be equivalent to $1.7 \%$ sodium chloride solution with the final volume of $50 \mathrm{~mL}$. For the second part, $\mathrm{SH}(0.6 \mathrm{~g})$ was dissolved into $50 \mathrm{~mL}$ ultra-pure water and mixed with the first part.

The preparation process of AZI-HPMC eye drops was also divided into two parts. For the first part, AZI (1 g) was precisely weighed and dispersed into $40 \mathrm{~mL}$ ultra-pure water. The dilute phosphoric acid $(1 \mathrm{~mol} / \mathrm{L})$ was slowly added with rapid stirring until the $\mathrm{pH}$ was 5.5 . For the second part, HPMC was dissolved into $50 \mathrm{~mL}$ hot water at $80-90{ }^{\circ} \mathrm{C}$, and then the solution was stirred until cooling to the room temperature. These two parts were mixed together to obtain the $1 \%$ AZI eye drops and the osmotic pressure was adjusted with sodium chloride solution $(2 \mathrm{~mol} / \mathrm{L})$ with the final volume of $100 \mathrm{~mL}$.

The prepared homogeneous solution of AZI-SH and AZI-HPMC eye drops was filtered through a $0.22 \mu \mathrm{m}$ filter. The complexes of AZI-SH and AZI-HPMC were obtained from the lyophilized powders of the prepared eye drops.

\subsubsection{Differential Scanning Calorimetry (DSC)}

Drug-polymer interaction was investigated by differential scanning calorimetry (DSC), which was carried out on a DSC 250 detector (Pyris Diamond TG/DTA, PerkinElmer, Waltham, MA, USA). The investigated samples ( $5 \mathrm{mg}$ ) were sealed into a platinum crucible. DSC scan was recorded in the range of $30^{\circ} \mathrm{C}$ to $350{ }^{\circ} \mathrm{C}$ at a heating rate of $10^{\circ} \mathrm{C} / \mathrm{min}$ under a nitrogen purge, and an empty pan was used as a reference. The analyses were performed for pure AZI, SH, AZI-SH, physical mixture of AZI and SH.

\subsubsection{X-Ray Diffraction Analysis}

X-ray diffraction (XRD) was measured at D8 Advance X-ray Diffractometer (Bruker-AXS company, Karlsruhe, Germany) using Cu K $\alpha$ radiation $(\lambda=1.54 \AA$ ) and APEX II CCD detector. Diffraction angle 2-Theta scale was measured in range from $3^{\circ}$ to $40^{\circ}$ with step size $0.02^{\circ}$ at speed $4 \% \mathrm{~min}$. Generator was operated at current $40 \mathrm{~mA}$ and voltage $40 \mathrm{kV}$. XRD analysis was performed using AZI, SH, AZI-SH and physical mixture of AZI and SH.

\subsection{5. ${ }^{1} \mathrm{H}-\mathrm{Nuclear}$ Magnetic Resonance Spectroscopy $\left({ }^{1} \mathrm{H}-\mathrm{NMR}\right)$}

The ${ }^{1} \mathrm{H}-\mathrm{NMR}$ of AZI, SH, AZI-SH and physical mixture of AZI and SH dissolved in the mixture of acetic acid-d6 and $\mathrm{D}_{2} \mathrm{O}(2: 100, v / v)$ were performed with a Varian $500 \mathrm{MHz}$ NMR spectrometer (Bruker, Faellanden, Switzerland) at $25^{\circ} \mathrm{C}$.

\subsubsection{Rheological Study}

The viscosity of the prepared AZI-SH and AZI-HPMC formulations was determined on a cone $\left(0.8^{\circ}\right)$ and plate geometry viscometer (Brookfield DV-IIIULTRA, Middleboro, MA, USA) equipped with a spindle SC4-16 at $37 \pm 1^{\circ} \mathrm{C}$. The viscosity of each formulation was measured under the varied 
rotational speed increased from 25 to $220 \mathrm{rpm}$, maintained at the largest speed for $6 \mathrm{~s}$, and decreased from 220 to $25 \mathrm{rpm}$. The average record of increase and decrease rotational speed was used to evaluate the rheological behavior of AZI-SH, AZI-HPMC formulations, blank SH and blank HPMC. Experiments were done in triplicate.

\subsubsection{Azithromycin Quantification by HPLC}

The HPLC analysis of AZI was carried out on a DIONEX Ultimate 3000 HPLC system (ThermoFisher, Waltham, MA, USA). Chromeleon 7 software was used for process monitoring, data acquisition and system control. A reversed phase C18 column (Phenomenex luna C18, $5 \mu \mathrm{m}$, $150 \mathrm{~mm} \times 4.6 \mathrm{~mm}$ ) was used for separation and maintained at $40{ }^{\circ} \mathrm{C}$. The mobile phase, composed of phosphate buffer $(0.05 \mathrm{~mol} / \mathrm{L}$ dipotassium phosphate with $\mathrm{pH}$ value of 8.2 adjusted by $20 \%$ phosphoric acid solution): acetonitrile (45:55) was used at a flow rate of $1.2 \mathrm{~mL} / \mathrm{min}$ with an isocratic elution. AZI was detected at $215 \mathrm{~nm}$ by UV detector. The calibration curve showed a good linearity $\left(r^{2}>0.99\right)$. The limit of quantification detection (LOD) was $0.5 \mu \mathrm{g} / \mathrm{mL}$.

\subsubsection{Precorneal Pharmcokinetic Study}

New Zealand albino rabbits were housed under standard environmental conditions $\left(25{ }^{\circ} \mathrm{C}, \mathrm{RH}\right.$ $50 \%$, and $12 \mathrm{~h} \mathrm{light/dark}$ cycle) with free access to food and water. 10 rabbits were used to determine precorneal pharmacokinetics of AZI. Each rabbit was instilled with $50 \mu \mathrm{L}$ 1\% AZI-SH eye drops prepared according to Section 2.2.2 on the right eye, and $50 \mu \mathrm{L} \mathrm{1 \%} \mathrm{AZI-HPMC} \mathrm{eye} \mathrm{drops} \mathrm{prepared}$ according to Section 2.2.2 on the left eye, respectively. At the predetermined time points, tears were collected by Schirmer test [25,26]. Briefly, tear samples of both eyes were collected at 5, 10, 20, 30, 45, 60 min after instillation by Schirmer test strips. The amount of tear collected was equal to the gained weight of each strip after sampling. The eyelids were gently held to close during sampling to prevent the loss of eye drops. Subsequently, the Schirmer strip was dried under $\mathrm{N}_{2}$ stream and $200 \mu \mathrm{L}$ of mobile phase was added. The sample was then vortexed to dissolve AZI and centrifuged under $300 \mathrm{~g}$ for $10 \mathrm{~min}$. The content of AZI in the supernatant was quantified by HPLC and the amount of AZI was calculated and presented as mg per $\mathrm{g}$ of the tears. Pharmacokinetic parameters of AZI, including $\mathrm{C}_{\max }, \mathrm{T}_{\max }$ and $\mathrm{AUC}_{0-\mathrm{t}}$, were calculated based on the obtained pharmacokinetic profiles by WinNonlin software.

\subsubsection{Safety Evaluation}

\section{Cytotoxicity Assay}

The cytotoxicity of AZI-SH eye drops in vitro was evaluated via 3-(4,5-dimethyl-2-Thiazyl)-2, 5-diphenyl-2H-tetrazolium bromide assay (MTT assay) and Neutral red uptake assay (NRU assay). 3T3-L1 cells were cultured in Dulbecco's modified Eagle's medium (DMEM) which contained 10\% $(v / v)$ fetal bovine serum, $100 \mathrm{IU} / \mathrm{mL}$ penicillin $\mathrm{G}$ and streptomycin, and $2 \mathrm{mM}$ L-glutamine at $37^{\circ} \mathrm{C}$ with $5 \% \mathrm{CO}_{2}$ and air humidified atmosphere. 3T3-L1 cells were exposed to different concentrations of BZK solution, AZI-SH eye drops and commercial AZI eye drops diluted by medium for $24 \mathrm{~h}$. Each concentration was tested in triplicates. DMSO (0.5\%) served as the solvent control. The cell viability was then detected by MTT assay. MTT solution $(20 \mu \mathrm{L}, 5 \mathrm{mg} / \mathrm{mL})$ was added into each well and incubated for $4 \mathrm{~h}$. Then, the MTT-containing medium was removed and $200 \mu \mathrm{L}$ of DMSO was added. The absorbance was measured at $490 \mathrm{~nm}$ by microplate reader (MD Spectramac M3, San Jose, CA, USA). The cell inhibition rate was calculated using Equation (1):

$$
\text { Cell inhibition rate }(\%)=\left(1-\frac{I_{\text {sample }}-I_{\text {blank }}}{I_{\text {control }}-I_{\text {blank }}}\right) \times 100 \% \text {, }
$$

where $I_{\text {sample }}$ and $I_{\text {control }}$ are the mean absorbance values of tested group and control group, respectively. $I_{\text {blank }}$ is the absorbance value of the medium. 
As for the NRU assay, 3T3-L1 cells were treated with the same concentrations of BZK solution, AZI-SH eye drops and commercial AZI eye drops. After the treatment, cells were incubated with a $200 \mu \mathrm{L}$ medium containing neutral red dye $(50 \mu \mathrm{g} / \mathrm{mL})$ for $3 \mathrm{~h}$. Cells were then washed three times with (phosphate buffer saline) PBS and the dye was extracted with $200 \mu \mathrm{L}$ destaining solution (deionised water, ethanol and glacial acetic acid, 49:50:1 v/v). The absorbance was measured at $540 \mathrm{~nm}$ using a microplate reader. Cell viability expressed as percentage of control and medium effective dose $\left(E D_{50}\right)$, the concentration of $50 \%$ reduction in dye uptake, were calculated by the same method described in the MTT assay.

The cytotoxicity of AZI-SH eye drops in vitro was also evaluated via MTT assay toward human corneal epithelial cells (HCE-2). The detailed experiments were listed in Supplementary information.

\section{In Vivo Eye Rrritation Assessment in Rabbits}

10 New Zealand albino rabbits were used to assess the ocular irritation of AZI-SH eye drops according to the Draize eye test [27]. Rabbits were checked to ensure no ocular defects before experiments. Approximately $50 \mu \mathrm{L}$ of AZI-SH eye drops (1\%) was dropped into the conjunctival sac of the right eye of each animal. The lids were held together after administration to prevent loss. The left eye without any treatment was regarded as control. Rabbits were treated with AZI-SH eye drops once a day for two weeks. After the treatment, rabbits' eyes were washed with saline to remove the residues of the drug [28]. Irritation was scored based on the criterion of Draize test, and the responses were evaluated and listed in Tables S1 and S2, expressed as the maximum average score [20,29].

Upon completion of the eye irritation study, rabbits were sacrificed by air embolism under anesthesia. Eyeballs were removed, fixed in $10 \%$ formalin solution and embedded in paraffin for further pathological examination. Histologic examinations of cornea, iris, screla and conjunctiva components were conducted with a light microscopy (T8-100, Nikon, Tokyo, Japan). The following aspects of eyeballs were checked, including variation of the ocular surface epithelial cells, edema in lid tissues, presence of inflammatory cells and any other abnormality [30].

\section{Acute Toxicity Test}

Eight healthy New Zealand albino rabbits without any eye irritation, corneal or conjunctival defects were used for the acute toxicity study. The rabbits were divided into two groups. One group were treated with 3\% AZI-SH eye drops (high concentration) in two eyes every four hours for twice, to ensure the total amount was equivalent to 200 times of normal daily dosage, while the other group were given saline into two eyes as the control. The instillation operation was the same as the processes described in eye irritation test in Section 2.2.8. Changes in ocular tissues in animals were evaluated at predetermined time points after treatment.

\subsubsection{Statistical Analysis}

All values are represented as mean \pm standard deviation (SD). The significant differences were evaluated by SPSS using a standard Student's $t$-test. Values of $P<0.05$ were regarded as statistical significant.

\section{Results}

\subsection{Degradation Kinetics of Azithromycin}

It is commonly recognized that solubility and stability properties of active pharmaceutical ingredients (APIs) are the major contributing factors for a formulation. The poor solubility of AZI, however, renders it hard to formulate a liquid dosage form. To solve this problem, acidic solutions were proposed to increase the solubility of AZI. It has been reported that the mass solubility of AZI can increase up to $1000 \mathrm{~g} / \mathrm{L}$ over the range of $\mathrm{pH} 1-6$ at $25^{\circ} \mathrm{C}$ and is $100 \mathrm{~g} / \mathrm{L}$ at $\mathrm{pH} 7$ [31]. The stability of AZI formulation under different $\mathrm{pH}$ values should be monitored to achieve a good balance of solubility and 
stability. In this study, the degradation kinetics and acid-alkali ionization constant of AZI in different phosphate buffer solutions with different $\mathrm{pH}$ values were investigated.

As shown in Figure $1 \mathrm{~A}, \ln \mathrm{C}_{\mathrm{AZI}}$ at predetermined intervals was plotted against time $(t)$. The hydrolysis reaction obeyed the first-order kinetics (Equation (2)) owing to the linearity of these plots. The acid-alkali ionization constants $(\mathrm{K})$ in Table 1 were obtained from the slopes of the lines (Figure $1 \mathrm{~A}$ ) as follows:

$$
\ln C_{A Z I}=\ln C_{A Z I, 0}-K t
$$

where $C_{A Z I}$ is the concentration of AZI at the $t(\mathrm{~h})$ and $\mathrm{C}_{\mathrm{AZI}, 0}$ is the initial concentration of AZI.

$\operatorname{lnK}$ values were plotted against $\mathrm{pH}$ values (Figure $1 \mathrm{~B}$ ). A turn of this curve was observed over $\mathrm{pH}$ values of 4.1-8.0, which indicated that AZI was deprotonated to the free alkali form. The lowest point was located at $\mathrm{pH} 6.0$ where AZI possessed the best stability $\left(\mathrm{pH}_{\mathrm{m}}\right)$. The degradation of AZI began to increase when $\mathrm{pH}$ below or above 6.0. The hydrolysis rate of AZI also took the same tendency. Moreover, the increase of hydrolysis rate was sharp when the $\mathrm{pH}$ decreased below 6.0, while only a slight increase of hydrolysis rate occurred with the $\mathrm{pH}$ increasing above 6.0. Since there was an ester bond in the structure of AZI, we speculated that the increase in degradation might be caused by the acidic and alkali dual-catalyzed hydrolysis. Taking the results of Box-behnken Design (data not shown) into the consideration, $\mathrm{pH} 5.5$ was chosen for AZI formulation, which was an acceptable $\mathrm{pH}$ for ophthalmic preparation [32].
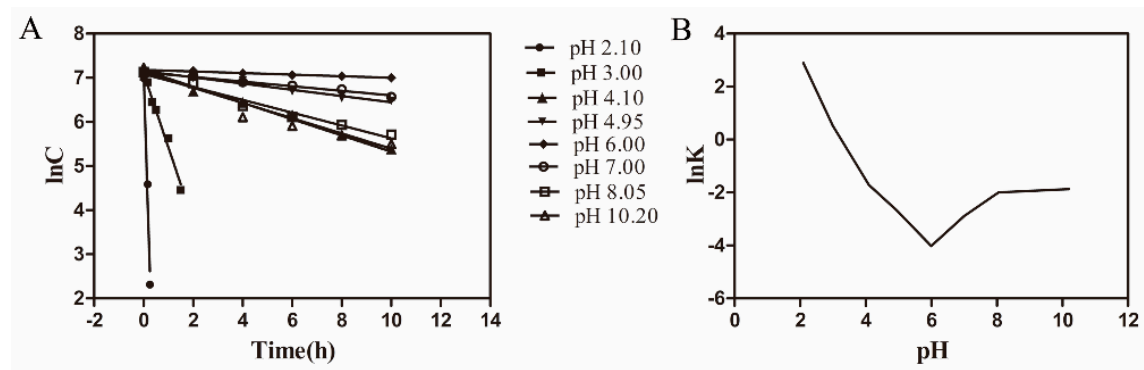

Figure 1. Degradation kinetics of azithromycin. A: Apparent first-order plot of azithromycin (AZI) hydrolysis at various $\mathrm{pH}$ values. Temperature was $75^{\circ} \mathrm{C}$ and ionic strength $(I)=0.3$. B: the hydrolysis of AZI at various $\mathrm{pH}, 75^{\circ} \mathrm{C}$ and $I=0.3$.

Table 1. Rate constants $(K)$ for the degradation of AZI in aqueous solution at different $\mathrm{pH}$ values (1-10).

\begin{tabular}{cccc}
\hline $\mathbf{p H}$ & $\boldsymbol{K}\left(\mathbf{h}^{\mathbf{- 1}}\right)$ & $\boldsymbol{l n} \boldsymbol{K}$ & $\boldsymbol{R}$ \\
\hline 2.1 & 18.1000 & 2.90 & 0.9849 \\
3.0 & 1.6747 & 0.52 & 0.9955 \\
4.1 & 0.1805 & -1.71 & 0.9965 \\
4.95 & 0.0689 & -2.68 & 0.9947 \\
6.0 & 0.0179 & -4.02 & 0.9953 \\
7.0 & 0.0557 & -2.89 & 0.9918 \\
8.05 & 0.1354 & -2.00 & 0.9849 \\
10.2 & 0.1534 & -1.87 & 0.9852 \\
\hline
\end{tabular}

Temperature was $75^{\circ} \mathrm{C}$, ionic strength $(I)=0.3$, and $R$ is the linear correlation coefficient.

\subsection{Differential Scanning Calorimetry (DSC)}

DSC was used to investigate the interaction between AZI and SH. AZI, SH, physical mixture of $\mathrm{AZI}$ and $\mathrm{SH}$ and the complex of AZI-SH were examined in the present study. DSC thermograms were depicted in Figure 2A. AZI has a broad melting peak on DSC thermogram, which has been ascribed to the departure of crystalline water simultaneously when melting. AZI from different manufactures were found to exhibit variable thermal, most of them exhibited two typical endotherms [33]. In the DSC thermogram of pure AZI, sharp melting endotherms appeared at $140{ }^{\circ} \mathrm{C}$ and $226^{\circ} \mathrm{C}$, which 
pointed out its melting points and suggested the crystal structure of AZI. In DSC thermogram of pure $\mathrm{SH}$, an endothermic peak at $196^{\circ} \mathrm{C}$ and an exothermic peak at $226^{\circ} \mathrm{C}$ were observed, which were consistent with previous reports [34]. The thermogram observed from physical mixture of AZI with $\mathrm{SH}$ was similar with the thermal behavior of pure AZI and SH. Moreover, intensity of the first peak of AZI was decreased in the physical mixture thermogram which could be explained by dilution effect of polymer, while intensity of the second peak was increased owing to the merging of endothermic peaks between AZI and SH. However, the typical melting endotherms of AZI were disappeared in the thermogram of AZI-SH, suggesting the structure transformation from crystalline form to amorphous form. In addition, the endothermic peak of $\mathrm{SH}$ was shifted to $184{ }^{\circ} \mathrm{C}$ and several new endothermic peaks appeared among the range from 200 to $225^{\circ} \mathrm{C}$. Based on the results of the thermograms of AZI, $\mathrm{SH}$ and $\mathrm{AZI}-\mathrm{SH}$, we hypothesized that the carboxyl group of SH could interact with the tertiary amine group of AZI to form the complex of AZI-SH.
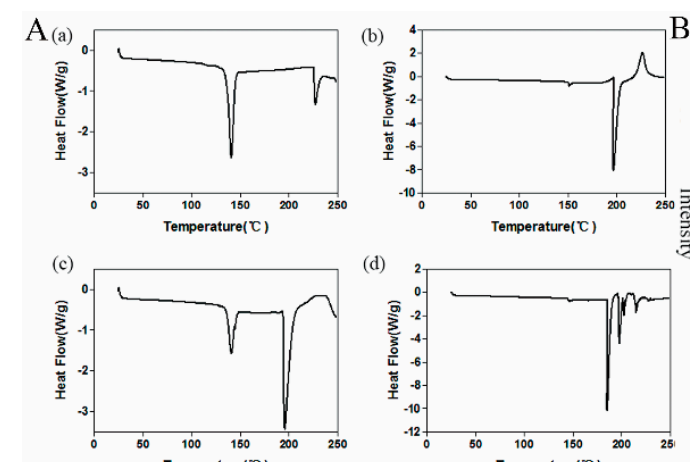

C
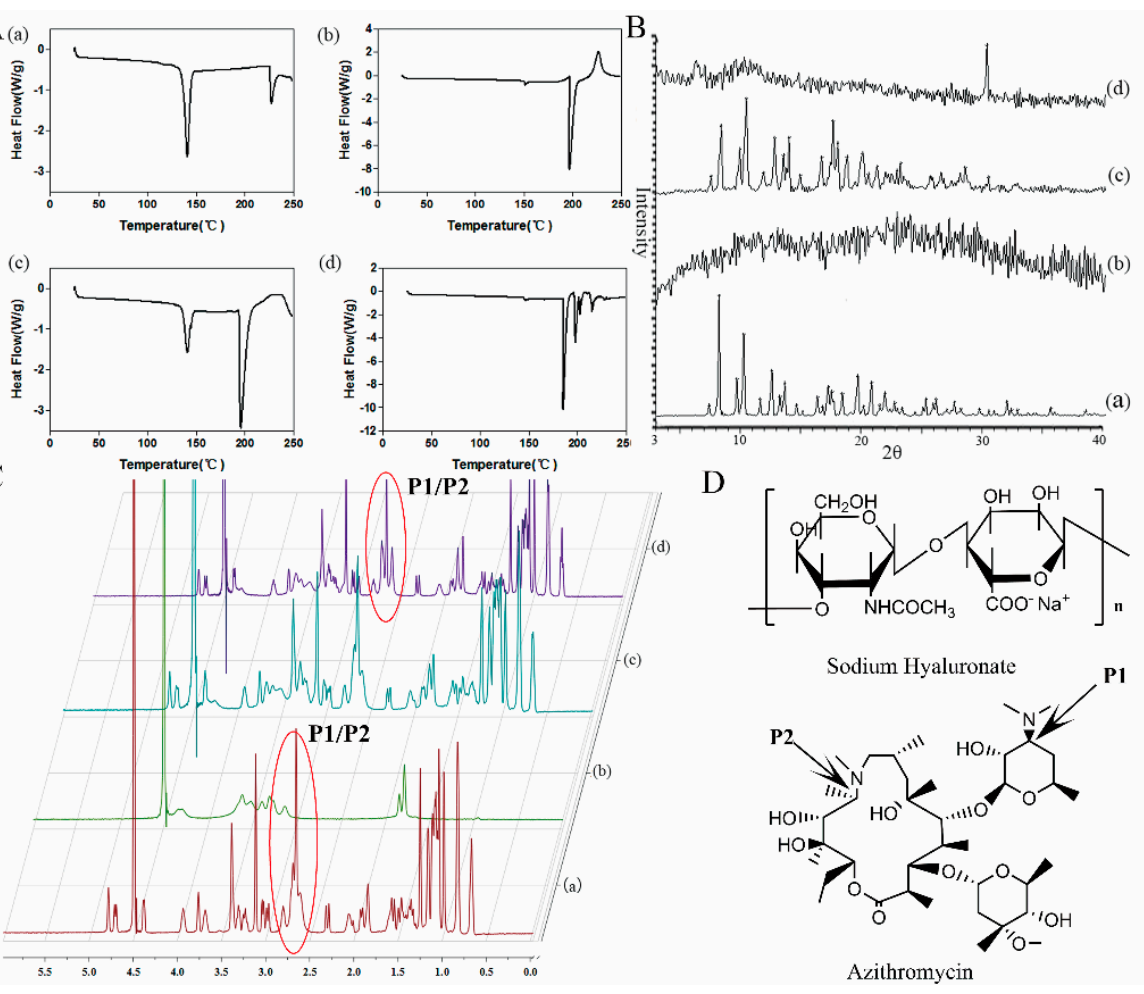

Figure 2. Illustration of interaction between AZI and sodium hyaluronate (SH). A: Differential Scanning Calorimetry (DSC) thermograms; B: X-ray diffraction (XRD) patterns; C: ${ }^{1} \mathrm{H}-\mathrm{Nuclear}$ Magnetic Resonance $\left({ }^{1} \mathrm{H}-\mathrm{NMR}\right)$ spectra. (a) AZI, (b) $\mathrm{SH}$, (c) physical mixture of AZI+SH and (d) AZI-SH complex. D: structure of sodium hyaluronate and azithromycin.

\subsection{XRD Analysis}

XRD was performed to confirm the crystalline conversion of $\mathrm{SH}$ and AZI. As shown in Figure 2B, only broad spectrum was detected for $\mathrm{SH}$, which was consistent with the amorphous form of this polymer. Several different peaks over a wide range of values were clearly shown in the diffraction of AZI, which demonstrated the crystal structure of AZI. The pattern of physical mixture of AZI and SH was almost similar to that of AZI, which was consistent with the results of DSC. However, the absence of typical peaks of pure AZI in the spectrum of AZI-SH complex suggested the scarcity of crystal structure of AZI. On the other hand, AZI-SH complex showed a novel diffraction peak around $30^{\circ}$, indicating the forming of a new crystalline structure, which might result from an interaction between AZI and SH in the AZI-SH complex. 


\section{4. ${ }^{1} H-N M R$ Analysis}

${ }^{1} \mathrm{H}-\mathrm{NMR}$ analyses were performed to precisely illustrate the interaction between AZI and SH. The spectra of SH, AZI, physical mixture of AZI and SH and AZI-SH complex were shown in Figure 2C. No significant changes of AZI signals were observed in the AZI-SH complex when compared to the spectra of AZI alone, while signals of the physical mixture of AZI and SH were the combination of both compounds. Due to significant signal overlap in most parts of the proton spectrum, the changes could only be obtained in the region between approximately 2.5 and $3.0 \mathrm{ppm}$. The germinal protons of P1 and P2 (Figure 2D) in AZI had signals at 2.5-3.0 ppm. This peak turned out to be an irregular quartet peak at $2.86 \mathrm{ppm}$. However, the peak at the same chemical shift was spilt to an irregular triplet peak and an irregular singlet peak in the spectra of AZI-SH. It was speculated that the tertiary amine group of AZI could turn into a positively charged center which would attract electrons and interact with the carboxyl group of SH bearing the negative charge. The results from DSC, XRD and NMR indicated that AZI could interact with SH in mild acid to form a new complex.

\subsection{Rheological Study}

The retention time of different formulations on the eye surface has been reported to be significantly affected by their rheology behaviors [35]. The increased viscosity value can increase the retention time of formulations on the application area especially for topical formulations [36]. However, it has been proved that the addition of water-soluble polymer excipient into eye drops only delayed the elimination of drugs in the first few minutes, but not improve local bioavailability significantly [37]. Therefore, it is necessary to investigate the rheology behaviors of AZI-SH and AZI-HPMC eye formulations to evaluate whether the viscosity of these two formulations affects the retention time of the formulations and the bioavailability of AZI.

The experiments were conducted at the rotational speed ranging from 25 to $220 \mathrm{rpm}$. As shown in Figure 3, the shearing thinning property indicated the pseudo-plastic rheology of these two formulations. In this flow behavior, an enhanced shearing speed led to an increase of shear stress, which facilitated drugs to be entrapped in the cross-linked network. On the contrary, drugs could be released along the flow when the viscosity decreased due to shearing [38].

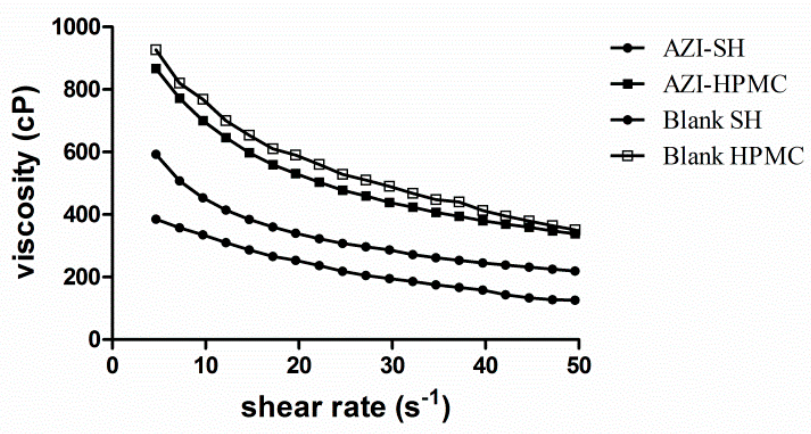

Figure 3. Comparison of the viscosity between AZI-SH formulation, AZI-HPMC formulation, blank SH and blank HPMC.

On the one hand, the viscosity value decreased with the increase of shearing force when the shearing rate altered in the range of $4.69-49.54 \mathrm{~s}^{-1}$ at room temperature (Figure 3). Shear thinning property is always expected since preparations should thin during application and thicken otherwise, for the blinking rate is rapid, ranging from $0.03 \mathrm{~s}^{-1}$ during inter-blinking periods to $4250-28,500 \mathrm{~s}^{-1}$ during blinking $[39,40]$. At the same time, it was further shown that the viscosity of HPMC eye drops was three times higher than that of SH eye drops. A higher viscosity might improve the retention time but may cause discomfort and blurred vision, which leads to poor treatment compliance. However, a lower viscosity might be easily washed by tears, thus resulting in the lower drug efficacy. Viscoelastic fluid, with the advantages that the viscosity becomes high when sheared low and becomes low when 
sheared quickly, could spread readily on the ocular surface to increase bioavailability and provide a better compliance of patients.

On the other hand, it can be concluded from the comparison of AZI-SH formulation and blank SH that formation of AZI-SH complex will decrease the viscosity of $\mathrm{SH}$, while the viscosity of AZI-HPMC formulation has only decreased slightly with no significant change comparing with the blank HPMC.

\subsection{Precorneal Pharmacokinetic Study}

In vivo precorneal pharmacokinetic studies were carried out to compare the ocular pharmacokinetic profiles of AZI-HPMC and AZI-SH preparations. The concentration-time profiles for AZI after topical instillation of these two kinds of formulations to the rabbit eyes in precorneal are shown in Figure 4. The $C_{\max }$ for AZI-SH was $6.59 \pm 0.92 \mathrm{mg} / \mathrm{mL}, 1.2$ times higher than that of AZI-HPMC, and the drug concentration of AZI-SH group at every sampling time point was higher than that of AZI-HPMC group. The drug concentration-time data were fitted by compartment model and the results were determined by Akaike's information criterion [39]. It was finally verified that this variation with time was in accord with two-compartment model, correlation coefficient $(R)>0.999$, which was consistent with previous studies that the double exponential function was the most similar function to the elimination curve of the drug in the conjunctival sac [41]. In any case, the elimination process always contains the rapid elimination phase and the subsequent slow elimination phase.

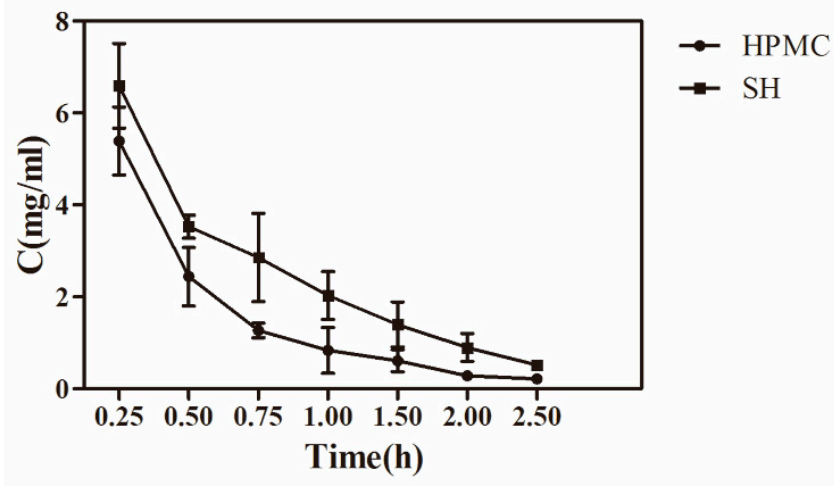

Figure 4. Concentration-time profiles of AZI in tear fluid after instillation of HPMC preparation and $\mathrm{SH}$ preparation in conscious rabbits $(n=5)$.

The specific pharmacokinetic parameters of AZI in tear fluid after topical administration was shown in Table 2. Parameters based on statistical moment theory (Table 3) for AZI were showing that the area under the curve (AUC) of AZI-SH and AZI-HPMC preparations were 7.30 and $4.60 \mathrm{mg} \times \mathrm{h} / \mathrm{mL}$, respectively, which indicated a significantly higher drug availability of AZI-SH preparation compared to AZI-HPMC preparation (1.58 times, $p<0.01$ ). The mean residence time (MRT) of AZI-SH preparation was 1.56 times higher than that of AZI-HPMC preparation $(p<0.05)$. The results of rheologic study and precorneal pharmacokinetic study suggested a better residence behavior of AZI-SH preparation, despite of a lower viscosity, due to the bioadhesive property of $\mathrm{SH}$ which had a high degree of viscoelasticity. The mucus covered by the ocular surface itself is a mixture of mucopolysaccharides, glycoproteins and some other related substances. Therefore, a large number of negatively charged carboxyl groups of $\mathrm{SH}$ molecules have a strong interaction with mucus network through hydrogen bonds [42].

The statistic results indicated that the AZI-SH preparation could lead to a slow elimination of AZI from the precorneal area due to the interaction between AZI and SH, which contributed to the increase of the precorneal residence and thus improving the ocular drug availability of AZI. 
Table 2. Pharmacokinetics parameters of AZI in tear fluid after topical administration in the conscious rabbits $(n=5)$.

\begin{tabular}{ccc}
\hline Pharmacokinetics Parameters & HPMC Group & SH Group \\
\hline $\mathrm{A}(\mu \mathrm{g} / \mathrm{mL})$ & 12.39 & 31.35 \\
$\alpha(1 / \mathrm{h})$ & 4.42 & 10.83 \\
$\mathrm{~B}(\mu \mathrm{g} / \mathrm{mL})$ & 1.58 & 5.34 \\
$\beta(1 / \mathrm{hr})$ & 0.81 & 0.90 \\
$\mathrm{~V}(\mathrm{c})(\mathrm{mg}) /(\mathrm{mg} / \mathrm{mL})$ & 71.60 & 13.63 \\
$\mathrm{~T}_{1 / 2 \alpha}(\mathrm{h})$ & 0.16 & 0.06 \\
$\mathrm{~T}_{1 / 2 \beta}(\mathrm{h})$ & 0.86 & 0.77 \\
$\mathrm{~K}_{21}(1 / \mathrm{h})$ & 1.22 & 2.3438 \\
$\mathrm{~K}_{10}(1 / \mathrm{h})$ & 2.94 & 4.15 \\
$\mathrm{~K}_{12}(1 / \mathrm{h})$ & 1.08 & 5.24 \\
$\mathrm{AUC}(\mathrm{mg} / \mathrm{mL}) \times \mathrm{h}$ & 4.76 & 8.85 \\
$\mathrm{CL}(\mathrm{s}) \mu \mathrm{g} / \mathrm{h} /(\mathrm{mg} / \mathrm{mL})$ & 210.18 & 56.52 \\
\hline
\end{tabular}

Table 3. Parameters based on statistical moment theory for AZI in tear fluid after topical administration in the conscious rabbits $(n=4)$.

\begin{tabular}{ccc}
\hline Pharmacokinetics Parameters & HPMC Group & SH Group \\
\hline Area under the curve $(\mathrm{AUC})(\mathrm{mg} \times \mathrm{h} / \mathrm{mL})$ & $4.60 \pm 0.51$ & $7.30 \pm 0.42$ \\
Area under the moment curve (AUMC) $\left(\mathrm{mg} \times \mathrm{h}^{2} / \mathrm{mL}\right)$ & $3.16 \pm 0.52$ & $7.77 \pm 0.58$ \\
Mean residence time $(\mathrm{MRT})(\mathrm{h}) * * *$ & $0.69 \pm 0.03$ & $1.07 \pm 0.05$ \\
Variance of the residence time $(\mathrm{VRT})(\mathrm{h} \times \mathrm{h})$ & $1.07 \pm 0.02$ & $1.61 \pm 0.02$ \\
\hline \multicolumn{2}{c}{$\left({ }^{* * *} p<0.05\right)}$.
\end{tabular}

\subsection{Safety Evaluation}

\subsubsection{Cytotoxicity Assay}

Two methods, including MTT and NRU assay, were used to evaluate cytotoxicity more comprehensively (Figure 5). These methods are both quantitative assays; the former is related to mitochondrial activity [43] and the latter depends on the uptake of NR into lysosomes [44]. Meanwhile, neutral red has been accepted officially by the French government for the evaluation of cosmetics [45]. The results of the MTT assay indicated that AZI-SH eye drops showed minimal toxicity in the range of $0.05-50 \mu \mathrm{g} / \mathrm{mL}$, while BZK caused severe cytotoxicity (Figure 5A). Based on the MTT assay, NRU assay was performed with the dosage of AZI-SH eye drops ranging from 0.25 to $80 \mu \mathrm{g} / \mathrm{mL}$. The results from both assays indicated that the toxicity of eye drops significantly increased with the concentration of BZK increased, suggesting that the toxicity of eye drops was associated with the addition of BZK, which has been recognized as the major toxic factor in eye drops [46]. BZK also showed a concentration- and time-dependent cytotoxicity, indicating that a higher concentration or a longer exposure of BZK caused much severe cytotoxicity [47]. The use of macromolecules such as SH and polycarbophil significantly decreased the toxicity of BZK, evidenced in Table 4 by the significantly higher half-maximal inhibitory concentration $\left(\mathrm{IC}_{50}\right)\left(5.71\right.$ times) and $\mathrm{ED}_{50}$ (4.19 times) of AZI-SH eye drops compared to that of $\mathrm{BZK}$ solution. The $\mathrm{IC}_{50}$ and $\mathrm{ED}_{50}$ of $\mathrm{AZI}-\mathrm{SH}$ eye drops was 1.17 times and 1.24 times higher than that of commercial AZI eye drops, suggesting a better protective effect of SH against BZK than polycarbophil. The findings were consistent with the results obtained from the MTT assay against HCE-2 cells (Figure S1). It has been reported that BZK could overproduce hydroperoxide and superoxide anion, leading to an oxidative stress [24]. However, the cationic quaternary ammonium of BZK which is harmful to eye tissues can be neutralized by the negative charges of SH. Meanwhile, $\mathrm{SH}$ contains a large number of hydroxyl groups, which can absorb reactive oxygen species produced by BZK. Therefore, $\mathrm{SH}$ is an effective agent against BZK-induced cytotoxicity, which is accordance with previous findings [24,48]. 

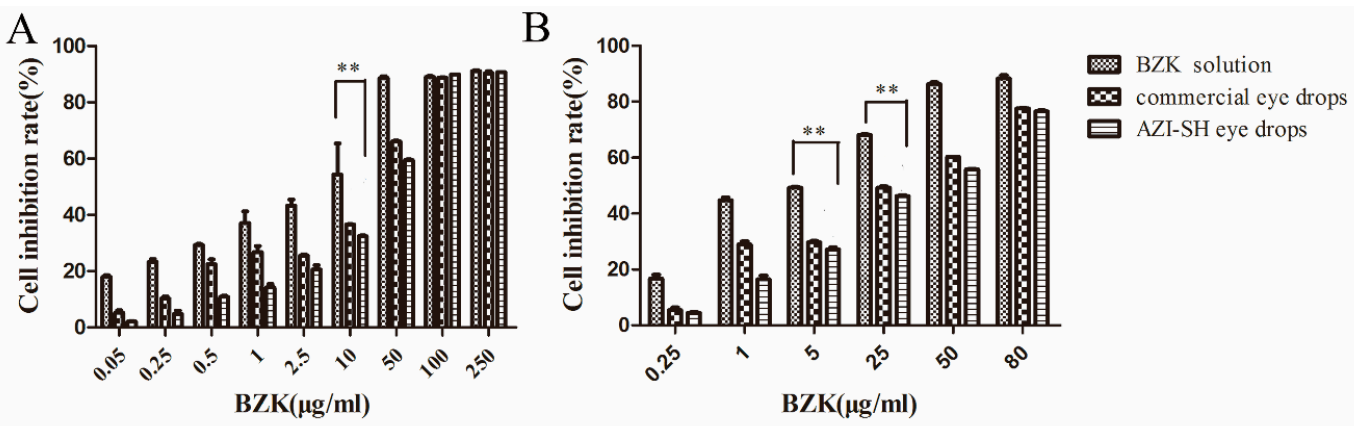

Figure 5. Cell viability against 3T3-L1 cells determined by MTT assay (A) and Neutral red uptake (NRU) assay $(\mathrm{B}) .\left({ }^{* *} P<0.01\right)$.

Table 4. IC50 and ED50 values of BZK solution, AZI-SH eye drops and commercial AZI eye drops in MTT assay and NRU assay.

\begin{tabular}{ccc}
\hline Groups & IC50 $(\mu \mathrm{g} / \mathrm{mL})$ & ED50 $(\mu \mathrm{g} / \mathrm{mL})$ \\
\hline BZK solution & $5.09 \pm 0.96$ & $9.69 \pm 5.66$ \\
AZI-SH eye drops & $29.07 \pm 1.87$ & $40.57 \pm 1.36^{*}$ \\
commercial AZI eye drops & $24.80 \pm 2.06$ & $32.79 \pm 0.48^{*}$ \\
\hline & $\left({ }^{*} P<0.01\right)$. &
\end{tabular}

\subsubsection{In Vivo Eye Irritation Assessment in Rabbits}

Evaluation and classification standard of rabbit eye irritation was referred to the new drug preclinical research guidelines issued by the Ministry of Health in China. During the whole processes, no deaths occurred by instillation and no obvious changes in rabbits' behavior were observed. The scores of irritation reactions of cornea, conjunctiva and iris were assessed. The comprehensive average score of the eye irritation response of the left eye given sterile saline was 0.25 , the average score of the eye irritation response of the right eye given AZI-SH eyedrops was 0.25 , indicating that the product had no eye irritation. The histological images of the major tissues (cornea, conjunctiva, sclera and iris) using hematoxylin and eosin staining are shown in Figure 6. Similar to the saline group, no noticeable tissue damage and no significant difference of the irritation scores between the treatment and control groups were observed. The results indicated that AZI eye drops did not show any irritation to rabbits' eyes.

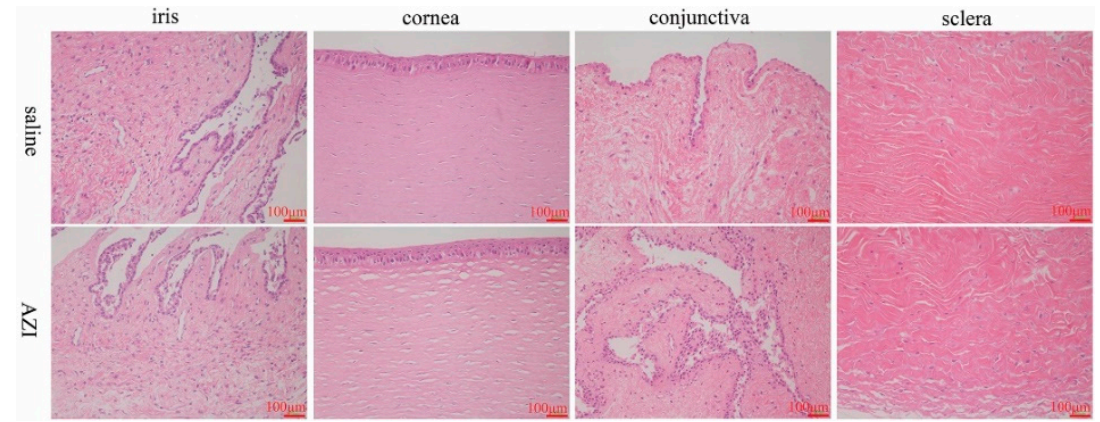

Figure 6. Evaluation of eye irritation by histopathological examinations of iris, cornea, conjunctiva and sclera.

\subsubsection{Acute Toxicity Test in Rabbits}

For the acute toxicity test, the pupil changes of rabbits treated with a high concentration of AZI-SH eye drops were monitored. The phenomenon of pupil variation was listed in Table S3. No significant changes of pupil were observed in both treatment and control group since. No obvious congestion was detected in the conjunctiva (palpebral conjunctiva, fornical conjunctiva and bulbar conjunctival) 
and iris. No cloudy symptom and ulcer of cornea and no abnormal secretions were observed. During the observation period, the AZI did not show any damages to rabbit local eye tissues or other tissues, which indicated that AZI eye drops would not cause any local or systemic toxicity.

\section{Conclusions}

A new AZI-SH eye drops formulation was developed, in which AZI and SH could form a complex under the mild acidic condition. By the biological adhesion advantage of $\mathrm{SH}$, this novel ocular preparation could extend precorneal residence and improve the ocular drug availability of AZI. In addition, the developed AZI-SH eye drops showed a good safety profile both in vitro and in vivo. Therefore, our findings indicated that this SH-based AZI eye drops was a promising formulation for topical drug delivery and ophthalmic therapy.

Supplementary Materials: The following are available online at http://www.mdpi.com/1999-4923/11/4/183/s1, Figure S1: Cell viability against HCE-2 cells determined by MTT assay, Table S1: Scores for grading the severity of ocular lesions/grading system in the ocular irritation tests, Table S2: Evaluation criteria for eye irritation reaction, Table S3: Influence of $3 \%$ azithromycin eye drops on rabbit papillary diameter $(\mathrm{cm}, n=4)$.

Author Contributions: Conceptualization, Q.C. and C.Y.; Formal analysis, Q.C.; Funding acquisition, J.T. and Y.S.; Investigation, Q.C. and C.Y.; Methodology, Q.C.; Project administration, J.T. and Y.S.; Resources, Y.S.; Supervision, J.T. and Y.S.; Validation, C.Y.; Writing—original draft, Q.C.; Writing—review \& editing, J.M. and Y.S.

Funding: This research was funded by the National Natural Science Foundation of China [NO. 81673364, NO.81501579], and the National Science and Technology Major Project of the Ministry of Science and Technology of China [NO.2017zx09101001].

Acknowledgments: Yipeng Su for review and editing. Qian Wang for expertise in animal anatomy and physiology.

Conflicts of Interest: The authors declare no conflict of interest.

\section{References}

1. Taylor, H.R. Trachoma-The future for a disease of the past. Br. J. Ophthalmol. 1993, 77, 66. [CrossRef]

2. Tung, N.T.; Tran, C.S.; Nguyen, T.L.; Hoang, T.; Trinh, T.D.; Nguyen, T.N. Formulation and biopharmaceutical evaluation of bitter taste masking microparticles containing azithromycin loaded in dispersible tablets. Eur. J. Pharm. Biopharm. 2017. [CrossRef]

3. Liu, F.; Porco, T.C.; Mkocha, H.A.; Muñoz, B.; Ray, K.J.; Bailey, R.L.; Lietman, T.M.; West, S.K. The efficacy of oral azithromycin in clearing ocular chlamydia: Mathematical modeling from a community-randomized trachoma trial. Epidemics 2014, 6, 10-17. [CrossRef]

4. Mohammadpour, M.; Abrishami, M.; Masoumi, A.; Hashemi, H. Trachoma: Past, present and future. J. Curr. Ophthalmol. 2016, 28, 165-169. [CrossRef]

5. Schachter, J.; West, S.K.; Mabey, D.; Dawson, C.R.; Bobo, L.; Bailey, R.; Vitale, S.; Quinn, T.C.; Sheta, A.; Sallam, S. Azithromycin in control of trachoma. Lancet 1999, 354, 630-635. [CrossRef]

6. Solomon, A.W. Trachoma Control: A Guide for Programme Managers; World Health Organization: Geneva, Switzerland, 2006; Volume 21, p. 42.

7. Urtti, A.; Pipkin, J.D.; Rork, G.; Sendo, T.; Finne, U.; Repta, A.J. Controlled drug delivery devices for experimental ocular studies with timolol 2. Ocular and systemic absorption in rabbits. Int. J. Pharm. 1990, 61, 241-249. [CrossRef]

8. Leeming, D.J.P. Treatment of Ocular Infections with Topical Antibacterials. Clin. Pharmacokinet. 1999, 37, 351-360. [CrossRef]

9. Bowman, L.M.; Si, E.; Pang, J.; Archibald, R.; Friedlaender, M. Development of a topical polymeric mucoadhesive ocular delivery system for azithromycin. J. Ocul. Pharmacol. Ther. 2009, 25, 133. [CrossRef]

10. Liu, Y.; Lin, X.; Tang, X. Lipid emulsions as a potential delivery system for ocular use of azithromycin. Drug Dev. Ind. Pharm. 2009, 35, 887. [CrossRef]

11. Salzillo, R.; Schiraldi, C.; Corsuto, L.; D'Agostino, A.; Filosa, R.; De, R.M.; La, G.A. Optimization of hyaluronan-based eye drop formulations. Carbohydr. Polym. 2016, 153, 275-283. [CrossRef] 
12. Aragona, P.; Papa, V.; Micali, A.; Santocono, M.; Milazzo, G. Long term treatment with sodium hyaluronate-containing artificial tears reduces ocular surface damage in patients with dry eye. Br. J. Ophthalmol. 2002, 86, 181-184. [CrossRef]

13. Jiménez, M.M.; Fresno, M.J.; Ramírez, A. Rheological study of binary gels with Carbopol Ultrez 10 and hyaluronic acid. Chem. Pharm. Bull. 2007, 55, 1157. [CrossRef] [PubMed]

14. Rozier, A.; Mazuel, C.; Grove, J.; Plazonnet, B. Functionality testing of gellan gum, a polymeric excipient material for ophthalmic dosage forms. Int. J. Pharm. 1997, 153, 191-198. [CrossRef]

15. Tatavarti, A.S.; Hoag, S.W. Microenvironmental pH modulation based release enhancement of a weakly basic drug from hydrophilic matrices. J. Pharm. Sci. 2006, 95, 1459-1468. [CrossRef]

16. Winterton, L.C.; Lally, J.M.; Sentell, K.B.; Chapoy, L.L. The elution of poly (vinyl alcohol) from a contact lens: The realization of a time release moisturizing agent/artificial tear. J. Biomed. Mater. Res. B Appl. Biomater. 2007, 80, 424. [CrossRef]

17. Abelson, M.; Protzko, E.; Shapiro, A.; Garces-Soldana, A.; Bowman, L. A randomized trial assessing the clinical efficacy and microbial eradication of $1 \%$ azithromycin ophthalmic solution vs tobramycin in adult and pediatric subjects with bacterial conjunctivitis. Clin. Ophthalmol. 2007, 1, 177-182.

18. Protzko, E.; Bowman, L.; Abelson, M.; Shapiro, A. Phase 3 safety comparisons for 1.0\% azithromycin in polymeric mucoadhesive eye drops versus $0.3 \%$ tobramycin eye drops for bacterial conjunctivitis. Investig. Ophthalmol. Vis. Sci. 2007, 48, 3425. [CrossRef]

19. Anirudhan, T.S.; Nair, S.S.; Nair, A.S. Fabrication of a bioadhesive transdermal device from chitosan and hyaluronic acid for the controlled release of lidocaine. Carbohydr. Polym. 2016, 152, 687-698. [CrossRef]

20. Kalam, M.A. Development of chitosan nanoparticles coated with hyaluronic acid for topical ocular delivery of dexamethasone. Int. J. Biol. Macromol. 2016, 89, 127-136. [CrossRef]

21. Vasi, A.M.; Popa, M.I.; Butnaru, M.; Dodi, G.; Verestiuc, L. Chemical functionalization of hyaluronic acid for drug delivery applications. Mater. Sci. Eng. C Mater. Biol. Appl. 2014, 38, 177-185. [CrossRef]

22. Härfstrand, A.; Molander, N.; Stenevi, U.; Apple, D.; Schenholm, M.; Madsen, K. Evidence of hyaluronic acid and hyaluronic acid binding sites on human corneal endothelium. J. Cataract. Refract. Surg. 1992, 18, 265-269. [CrossRef]

23. Liu, X.; Yu, F.F.; Zhong, Y.M.; Guo, X.X.; Mao, Z. Therapeutic Effects of Sodium Hyaluronate on Ocular Surface Damage Induced by Benzalkonium Chloride Preserved Anti-glaucoma Medications. Chin. Med. J. 2015, 128, 2444-2449. [CrossRef] [PubMed]

24. Pauloin, T.; Dutot, M.; Warnet, J.M.; Rat, P. In vitro modulation of preservative toxicity: High molecular weight hyaluronan decreases apoptosis and oxidative stress induced by benzalkonium chloride. Eur. J. Pharm. Sci. 2008, 34, 263-273. [CrossRef]

25. Langford, M.P.; Foreman, B.D.; Srur, L.; Ganley, J.P.; Redens, T.B. Bilateral acute pyogenic conjunctivitis with iritis induced by unilateral topical application of bacterial peptidoglycan muramyl dipeptide in adult rabbits. Exp. Eye Res. 2013, 116, 324. [CrossRef]

26. Schoenwald, R.D.; Vidvauns, S.; Wurster, D.E.; Barfknecht, C.F. Tear film stability of protein extracts from dry eye patients administered a sigma agonist. J. Ocul. Pharmacol. Ther. 1997, 13, 151-161. [CrossRef]

27. Wilhelmus, K.R. The Draize eye test. Surv. Ophthalmol. 2001, 45, 493-515. [CrossRef]

28. Kishore, A.S.; Surekha, P.; Murthy, P.B. Assessment of the dermal and ocular irritation potential of multi-walled carbon nanotubes by using in vitro and in vivo methods. Toxicol. Lett. 2009, 191, 268-274. [CrossRef]

29. Li, Q.; Li, Z.; Zeng, W.; Ge, S.; Lu, H.; Wu, C.; Ge, L.; Liang, D.; Xu, Y. Proniosome-derived niosomes for tacrolimus topical ocular delivery: In vitro cornea permeation, ocular irritation, and in vivo anti-allograft rejection. Eur J. Pharm. Sci. 2014, 62, 115. [CrossRef] [PubMed]

30. Diebold, Y.; Jarrín, M.; Sáez, V.; Carvalho, E.L.; Orea, M.; Calonge, M.; Seijo, B.; Alonso, M.J. Ocular drug delivery by liposome-chitosan nanoparticle complexes (LCS-NP). Biomaterials 2007, 28, 1553-1564. [CrossRef]

31. Zhang, Y.; Wang, X.; Lin, X.; Liu, X.; Tian, B.; Tang, X. High azithromycin loading powders for inhalation and their in vivo evaluation in rats. Int. J. Pharm. 2010, 395, 205. [CrossRef]

32. Li, Y.; Zhang, Y.; Li, P.; Mi, G.; Tu, J.; Sun, L.; Webster, T.J.; Shen, Y. Ion-paired pirenzepine-loaded micelles as an ophthalmic delivery system for the treatment of myopia. Nanomedicine 2017, 13, 2079-2089. [CrossRef] [PubMed] 
33. Kauss, T.; Gaubert, A.; Boyer, C.; Ba, B.B.; Manse, M.; Massip, S.; Léger, J.M.; Fawaz, F.; Lembege, M.; Boiron, J.M. Pharmaceutical development and optimization of azithromycin suppository for paediatric use. Int. J. Pharm. 2013, 441, 218-226. [CrossRef] [PubMed]

34. Khachatryan, G.; Khachatryan, K.; Grzyb, J.; Fiedorowicz, M. Formation and properties of hyaluronan/nano Ag and hyaluronan-lecithin/nano Ag films. Carbohydr. Polym. 2016, 151, 452-457. [CrossRef]

35. Edsman, K.; Carlfors, J.; Harju, K. Rheological evaluation and ocular contact time of some carbomer gels for ophthalmic use. Int. J. Pharm. 1996, 137, 233-241. [CrossRef]

36. Üstündağ-Okur, N.; Gökçe, E.H.; Bozbıyık, D.İ.; Eğrilmez, S.; Ozer, O.; Ertan, G. Preparation and in vitro-in vivo evaluation of ofloxacin loaded ophthalmic nano structured lipid carriers modified with chitosan oligosaccharide lactate for the treatment of bacterial keratitis. Eur. J. Pharm. Sci. 2014, 63, $204-215$. [CrossRef] [PubMed]

37. Ludwig, A.; Ooteghem, M.V. The evaluation of viscous ophthalmic vehicles by slit lamp fluorophotometry in humans. Int. J. Pharm. 1989, 54, 95-102. [CrossRef]

38. Parrott, E.L. Pharmaceutical Technology: Fundamental Pharmaceutics; Burgess Pub. Co.: Minneapolis, MN, USA, 1970.

39. Ozaki, T.; Oda, H. Non-Linear Time Series Model Identification by Akaike's Information Criterion. IFAC Proc. Vol. 1977, 10, 83-91. [CrossRef]

40. Bother, H.; Waaler, T. Rheological Characterization of Tear Substitutes. Drug Dev. Ind. Pharm. 2008, 16, 755-768. [CrossRef]

41. Durrani, A.M.; Farr, S.J.; Kellaway, I.W. Influence of molecular weight and formulation pH on the precorneal clearance rate of hyaluronic acid in the rabbit eye. Int. J. Pharm. 1995, 118, 243-250. [CrossRef]

42. Robinson, J.R.; Mlynek, G.M. Bioadhesive and phase-change polymers for ocular drug delivery. Adv. Drug Deliv. Rev. 1995, 16, 45-50. [CrossRef]

43. Denizot, F.; Lang, R. Rapid colorimetric assay for cell growth and survival. Modifications to the tetrazolium dye procedure giving improved sensitivity and reliability. J. Immunol. Methods 1986, 89, 271-277. [CrossRef]

44. Borenfreund, E.; Puerner, J.A. Toxicity determined in vitro by morphological alterations and neutral red absorption. Toxicol. Lett. 1985, 24, 119-124. [CrossRef]

45. Ubels, J.L.; Clousing, D.P. In Vitro Alternatives to the Use of Animals in Ocular Toxicology Testing. Ocul. Surf. 2005, 3, 126-142. [CrossRef]

46. Ayaki, M.; Iwasawa, A. Cell viability of four corneoconjunctival cell lines exposed to five preservatives and a surfactant used for infection control in eyedrops. Biocontrol Sci. 2011, 16, 117-121. [CrossRef]

47. Iwasawa, A.; Ayaki, M.; Niwano, Y. Cell viability score (CVS) as a good indicator of critical concentration of benzalkonium chloride for toxicity in cultured ocular surface cell lines. Regul. Toxicol. Pharmacol. 2013, 66, 177-183. [CrossRef] [PubMed]

48. Wu, H.; Zhang, H.; Wang, C.; Wu, Y.; Xie, J.; Jin, X.; Yang, J.; Ye, J. Genoprotective effect of hyaluronic acid against benzalkonium chloride-induced DNA damage in human corneal epithelial cells. Mol. Vis. 2011, 17, 3364-3370. [CrossRef] [PubMed]

(C) 2019 by the authors. Licensee MDPI, Basel, Switzerland. This article is an open access article distributed under the terms and conditions of the Creative Commons Attribution (CC BY) license (http://creativecommons.org/licenses/by/4.0/). 